\title{
UM ESTRANHO NO CORAÇÃO
}

\section{... breves considerações acerca de alguns aspectos psicológicos na transplantação}

\author{
Eduardo Sá \\ Psicólogo e psicanalista
}

1.

Há uma linha que une um cirurgião a um psicanalista: a imensa complexidade que está presente no desafio de intervir e a exigência duma rigorosa ponderação e dum rigor técnico preciso (que não deixa de existir quando "mexemos" no pensamento como no corpo duma pessoa). Mas, há um ponto que os separa: por mais transplantes que seja exequível realizar numa pessoa, a nossa intervenção junto do seu pensamento será menos invasiva, menos radical e mais conservadora.

Seja como for, de que forma pode ser útil uma compreensão, no âmbito da clínica psicológica, quando se reflecte acerca da transplantação? Em primeiro lugar, servirá para chamar, delicadamente, a vossa atenção que, por mais consensos clínicos e protocolos técnicos que vos unam, haverá uma variável que pode interferir, de forma significativa, no trabalho da equipa de transplantes: o psiquismo duma pessoa.

\section{Instituição: \\ Universidade de Coimbra; ISPA - Portugal}

\author{
Correspondência: \\ Eduardo Sá \\ E-mail: eduardosa@bebesecrescidos.com
}

Recebido em: 30/04/2013

Aceito em: 28/06/3013
Tomando em consideração essa variável, comecemos por um aspecto, aparentemente banal: se considerarmos a saúde como um bem-estar bio-psico-social, e se reconhecermos que a formação médica - hoje, inequivocamente mais tecnocrática e menos clínica - reúne mais critérios fidedignos para avaliar e intervir noutros domínios da saúde que não na saúde mental, pode ser útil uma brevíssima intervenção, no âmbito da psicologia, quando se fala transplantação, porque esta variável psíquica, deixada à margem dos cuidados integrados, contamina os cuidados médicos, enviesa muitas vezes a saúde, e, em inúmeras situações, inquina-a, mesmo.

É claro que haverá um temor inicial que me convida a ser prudente: receio que, ao falarmos aqui de doença psíquica, sejamos todos mais ou menos impelidos para configurar, num impulso, quadros relacionados com perturbações mentais muito exuberantes. Como se estivéssemos a supor que, ao falarmos de doença psíquica, pudéssemos resvalar para a consideração de quadros clínicos em torno dum colorido esquizofreniforme (e não tanto para um sofrimento psíquico que se enovela e se croniciza e que, em consequência, gera sintomas que, ao "calcificarem", contribuem para uma espécie de "osteoporose cognitiva" e para sequelas emocionais que geram, contribuem, parasitam ou complexificam todos os quadros da clínica médica).

Ora, como os doentes transplantados não deixam de ser pessoas, como nós, seria importante:

- em primeiro lugar, identificar, em paralelo com qualquer avaliação pré-transplante, marcadores psicopatológicos nestas pessoas [separando aqueles que são reactivos à doença e a todo o processo de transplantação - e que serão manifestações, tendencialmente, transversais nestes pacientes - das características psicopatológicas mais estruturais de cada uma das suas personalidades (que, 
necessariamente, têm mais probabilidades de se acentuar e de se agudizar ao longo do processo de transplante, interferindo, de diversas formas, nele)];

- em segundo lugar, de que modo é que estes marcadores psicopatológicos (reactivos ou estruturais) acompanham a doença e, de certa forma, interferem na sua expressão ou a comprometem;

- em terceiro lugar, de que forma estes marcadores psicopatológicos - representando variáveis que podem parasitar ou enviesar um processo com a delicadeza técnica, clínica e humana dum transplante - devem ser levados em linha de conta por uma equipa médica. E, já agora, de que modo devem ser manuseados;

- e, finalmente, de que forma estes marcadores interferem nos diversos momentos dum processo de transplante.

Façamos uma primeira abordagem, mais empírica, sobre alguns indicadores de doença psíquica na população, de forma a que tomemos consciência da sua existência, em primeiro lugar, para que, depois, possamos delinear um modo para os manusearmos, quando se trata de intervir no âmbito de uma equipa de transplantes.

Como é do vosso conhecimento, a Organização Mundial de Saúde considera que mais de $80 \%$ dos casos de doenças coronárias, $90 \%$ de diabetes tipo 2 e um terço dos quadros oncológicos poderiam ser evitadas pela alteração de hábitos alimentares, actividade física e consumo de tabaco, o que reforça a importância da capacitação dos indivíduos para a gestão responsável da sua própria saúde. Por outras palavras: há variáveis psicológicas (que não serão nem tão exuberantes nem tão incapacitantes a ponto de as considerarmos, empiricamente, doença psiquiátrica) que são muito preponderantes para dados tão esmagadores quanto estes. Não tomar em consideração estes factores de natureza psicológica pode comprometer a promoção da saúde, a prevenção da doença e, já agora, a gestão incisiva e eficaz dos recursos ao dispor dos doentes nos cuidados médicos.

Mas tomemos em consideração, muito rapidamente, outros indicadores de sofrimento psíquico crónico da população:

Em Portugal, os encargos do Serviço Nacional de Saúde com os psicofármacos - entre 2000 e 2009 - rondaram os 1,5 mil milhões de euros, segundo um estudo do Observatório do Medicamento do Infarmed (existindo uma tendência de crescimento que levou a que os 64,9 milhões de euros, gastos em 2000, se transformassem em 202,8 milhões de euros, despendidos em 2009, representando, em 9 anos, um crescimento de 213 por cento desse tipo de prescrições).

Se preferirem doutra maneira: em Portugal, nos últimos 5 anos, houve um aumento da prescrição de psicofarmacos na ordem dos $36,6 \%$, representando um consumo, nesse período, de 28 milhões de embalagens desses medicamentos, a que corresponde um gasto de 372 milhões de euros. A esse propósito, o Alto Comissariado para a Saúde regista que, para cada 1000 portugueses, há um consumo de 152 psicofarmacos, repartidos entre ansiolíticos, hipnóticos, sedativos e anti-depressivos.

Ou, ainda duma outra forma: em Portugal, entre Janeiro e Agosto de 2012, já foram vendidas em quase cinco milhões de unidades de anti-depressivos (4.970.062) - mais 329.292 unidades, ou 7,1 por cento - do que em igual período do ano passado (4.640.770). Recordo-vos que a população portuguesa andará em redor dos 10 milhões de pessoas...

Já no Brasil, o tranquilizante Rivotril é o medicamento mais vendido, depois do contraceptivo, e líder do ranking, Microvlar. Apesar de, numa pesquisa internacional, realizada para medir a perspectiva de felicidade da população em 132 países, e divulgada pelo centro de políticas sociais da Fundação Getúlio Vargas (FGV), ser claro ao afirmar que o povo brasileiro será o povo mais confiante em relação ao seu futuro, daqui a cinco anos, à frente de países como a Venezuela $(8,52)$ e, até mesmo, a Dinamarca $(8,51)$.

Por outras palavras, estou a tentar dizer-vos que - reacções psicológicas inerentes ao próprio processo de transplante à parte - há indicadores de sofrimento psíquico e de doença psíquica que são transversais a todos nós, que nos permitem dizer que (não correspondendo a quadros clínicos esquizofreniformes, como vos dizia) nos permitem reconhecer que a maioria das pessoas sofre, em graus diferentes, de doença psíquica, cujas manifestações, no caso dum transplante, podem interferir nos mais diversos momentos desse processo.

É claro que haverá alguns outros indicadores empíricos de doença psíquica que serão banais no dia-a-dia da vossa actividade clínica. Falo-vos de 4 dos mais banais:

- o stress crónico, com influência nítida a nível da patologia cardio-vascular;

- a personalidade de tipo A, que corresponde a uma contenção obsessiva clara, que faz com que a expressão dos afectos seja mediada por racionalizações repetidas, e que é uma característica "amiga" da doença coronária;

- a personalidade de tipo C, caracterizada por uma hostilidade permanente, resultante duma violência contida que estas pessoas manifestam, e que tem vindo a ser, insistentemente associada a quadros de natureza oncológica, quer no modo como interferem nas terapêuticas oncológicas e, até, no próprio processo oncogénico;

- e a depressividade (que, se preferirem, poderemos descrever como um estado de estar, permanentemente, triste) com uma interveniência relevante nos quadros 
neuro-iminitários (podendo influenciar, como factor adjuvante, a própria dinâmica imunitária envolvida na transplantação).

Cada uma das pessoas com estas características lida com a angústia, com o sofrimento ou com a dor de formas diferentes. Cada uma delas escuta de forma distinta. Cada uma delas reage, no período pré e pós-operatório, de modo próprio. Como compreenderão, estas características, podendo ser anteriores, nalgumas pessoas, ao processo de transplante, interferem nele, potenciando estados psicopatológicos reactivos ao próprio transplante. Seja como for, todas estas pessoas, por mais acompanhadas que estejam, sentir-se-ão, diante dum transplante, as pessoas mais desamparadas do mundo. E, muito mais que a dor física, é a experiência de desamparo que enviesa o sofrimento, o subjectiva e o potencia de forma geométrica. Interferindo, em todos esses momentos, nos processos imunitários.

Diante duma realidade como esta, a necessidade dum transplante, exigindo procedimentos estandardizados, será influenciada - antes da cirurgia, no contexto do internamento tendente à cirurgia e no período póscirúrgico - pelos recursos de saúde mental duma pessoa (e por aqueles que, de forma metódica, a própria equipa conseguir mobilizar). Inclusive, a nível psico-neuroimunológico. E, tornando mais aguda a complexidade duma avaliação psicológica como factor adjuvante ao diagnóstico pré-transplante, será, ainda, mais agravada pelas dinâmicas amorosa e/ou conjugal e familiar dessa pessoa. Vejamos três exemplos, mais ou menos aleatórios:

- Se, por exemplo, a família dum doente em transplantação se for revelando desmembrada, é plausível que, muito mais que quaisquer laços familiares, o transplante crie um conluio familiar que trará ganhos psíquicos secundários à própria família e, em concomitância, tornem a actuação da equipa de transplantes muito mais delicada em quaisquer momentos do processo de transplantação;

- Se um dos membros dum casal, claramente, deprimido for objecto duma transplantação, a exuberância do sofrimento, a polissemia das queixas e a dinâmica que ambas mobilizam pode transformar o casal num "abcesso tão calcificado" que o acesso da equipa ao doente transplantado se torna muito sinuoso;

- Se um doente em transplante for muito narcísico, por exemplo, os níveis de altivez e de arrogância que, geralmente, evidenciará poderão ser tais que, o critério de merecimento do transplante (por vezes, evocado) pode ser, em muitas circunstâncias, um factor de distorção da decisão duma equipa, unicamente em função da animosidade que um doente como esse não deixa de gerar;

- Já se, ao falarmos de transplantação, tomarmos em consideração o transplante duma criança ou dum adolescente, a dinâmica familiar pode ser tão enviesante e a hostilidade do doente poderá ser tão exuberante que, a par dos cuidados médico-cirúrgicos, haverá a necessidade dum rigor delicadíssimo, a nível psicológico e familiar, sem os quais o sucesso do próprio transplante pode ficar comprometido.

Este tipo de indicadores psicológicos (mais em rigor, psicopatológicos), muitas vezes sob medicação mas sem gestão ou resolução à vista (medicalizar o sofrimento não é nem geri-lo nem resolvê-lo) trazem consigo várias questões que, de forma empírica, qualquer médico colocará quase todos os dias. Que, não sendo procedimentos cirúrgicos, são muito exigentes no vosso trabalho diário, podendo infiltrar com leituras, perigosamente, empíricas a diferenciação de excepção duma equipa de transplantes. Vejamos, entre inúmeras outras, algumas destas questões com que as equipas de transplante lidam:

- De que forma se pode inflectir, quando é o caso, uma tendência de comportamentos próximos dum suicídio passivo dum determinado doente (relacionados com consumos alimentares ou com hábitos de trabalho promotores de stress crónico, por hipótese) com todas as implicações na saúde que eles têm, podendo, inclusive, comprometer o próprio transplante? Não serão estes doentes, a priori, menos merecedores dum transplante e mais necessitados dum acompanhamento psicológico consistente de forma a que reunam competências para que o venham a merecer?

- De que modo se transmite um diagnóstico que exija um transplante, e que alianças se têm de mobilizar para que haja uma adesão clara à cirurgia e aos tratamentos pré e pós-cirúrgico?

- Ou, por exemplo, de que modo é que um transplante altera, de forma radical, os estilos de vida e compromete a saúde mental duma pessoa, a sua relação conjugal ou a respectiva dinâmica familiar...

\section{2.}

Em resumo, para além do perfil psicológico de cada doente, os respectivos estilos de relação conjugal e a sua dinâmica familiar são factores preponderantes em todos os momentos dum processo transplante. Sem querer psicologizar a clínica médica, seria imprescindível que um técnico de saúde mental fosse integrado numa equipa de transplantes, não tanto para funcionar numa relação de face a face com estes doentes mas, antes, para que, na retaguarda da relação médico/doente, e em pleno contexto da própria equipa, "legende" comportamentos, diagnostique com rigor e parcimónia, proponha formatos adequados de informação, de interpretação de comportamentos e de medos silenciosos, e promova transformações na gestão 
das relações hospitalares e extra-hospitalares e nos recursos mentais do próprio doente que, no seu conjunto, terão um efeito multiplicativo na qualidade dos cuidados de que os doentes transplantados já dispõem.

Seja como for, o tempo de espera por um orgão, e todos os procedimentos médicos e cirúrgicos que antecedem o transplante, trazem níveis significativos de toxicidade ao funcionamento psíquico e às relações familiar, social e profissional destas pessoas. Que aumenta diante dos primeiros procedimentos de preparação para o transplante (que, nas crianças, por exemplo, vai implicar uma irascibilidade imensa, quer dirigida aos irmãos saudáveis quer em relação a um ou a ambos os pais). E se agudiza quando as limitações ao estilo de vida se tornam fracturantes - que, no caso dos adolescentes, implicará ora uma "incontinência de irascibilidade" ora atitudes de denegação das limitações que lhe são impostas. Por mais que, com ela, a situação clínica do adolescente o possa precipitar para condutas que se avizinhem a uma "roleta russa", com as quais delineia estratégias triunfais diante da angústia e da morte.

O colorido diante da espera do órgão depende, entre outros factores, do facto dele chegar via um dos pais ou doutro familiar (como nos transplantes renais) ou através dum dador, dependendo a reacção do órgão em questão. No caso dum transplante cujo dador será um familiar, a ambivalência de comportamentos pode assumir a vertigem duma "montanha russa", repartidos entre um sentimento de dívida exuberante como de episódios, intempestivos, de desdém. Já quando o dador é um dos cônjuges e o doente transplantado o outro, as "interferências relacionais" sobrem de tom, provocando, em muitas circunstâncias, uma perigosa anulação do cônjuge receptor em benefício do cônjuge dador, com tudo o que isso tem turbulento numa relação (como se, com o novo órgão, se ganhasse a vida e com a respectiva "factura" relacional o doente transplantado se sentisse precipitado no purgatório).

Ainda assim, as expressões da ira pelos doentes transplantados será um indicador de bom prognóstico. A ira é, sem dúvida, o melhor anti-depressivo do mundo. E, não sendo uma manifestação compulsiva, introduz uma expressão emocional em tudo melhor que uma atmosfera de comedimento racional e de resignação depressiva que têm, sem dúvida, "facturas psicológicas e relacionais" com custos gravíssimos no médio prazo.

Em quaisquer circunstâncias, é de esperar que, no período cirúrgico, a maioria das pessoas se adeque, de forma rigorosa, às solicitações e às prescrições do próprio médico. E que, em consequência da experiência de quase-morte que o transplante mobiliza, os índices macroscópicos de stress, de angústia e de depressão sejam, aparentemente, menores. Já quanto à insónia (nomeadamente, nocturna) a sua exuberância acentua-se no período cirúrgico, em virtude do pavor do doente transplantado vir a morrer a dormir.

Como em qualquer um de nós em experiências de quasemorte, é de esperar que um doente em pleno processo cirúrgico de transplantação colabore e se expresse de forma, tendencialmente, irrepreensível. Sobretudo porque, diante duma experiência de quase-morte, nenhum de nós manifesta, regra geral, nem angústia nem pânico generalizados. Antes funciona. Porque, em circunstâncias de quase morte, o terror nos aconselha, sobretudo, a sacrificar o que quer que seja para sobreviver.

Mas - atenção - num plano psíquico, e num primeiro momento, um órgão transplantado é sentido por uma pessoa como um enxerto! Será preciso muito tempo, e um suporte psicológico adequado da equipa de transplantes, ao doente transplantado e à sua família, para que um órgão transplantado seja assumido pelo próprio como parte de si. O tempo é um parceiro precioso no "metabolismo emocional" do órgão transplantado. Se, num primeiro momento, é de esperar que as dúvidas acerca do dador - existindo, todavia - sejam ignoradas, com os anos de transplante elas emergem podendo, nalguns destes doentes, tornar-se, mesmo, obsessivas.

A mim preocupam-me as sequelas psíquicas do transplante que precisam de emergir e... "disparar" à medida que os meses pós-transplante vão decorrendo. Não será, pois, estranho que 1 ou 2 anos depois dum transplante que - à medida que vão retomando as suas vidas familiar, social e profissional - estes doentes "afundem" depressivamente de forma exuberante, representando esse sofrimento, diferido e terrível, um sinal de bom prognóstico no metabolismo psíquico do transplante a longo prazo, manifestando-se de forma franca ou, com custos muito mais incalculáveis, de forma reciclada através de perturbações de carácter ou, por exemplo, de estilos de vida tão avidamente assépticos, esterilizados e hipocondríacos que os podem mortificar, por dentro, estas pessoas, em prestações sucessivas.

Chamo-vos, a este respeito, para o modo como, depois dum transplante, um doente transplantado se torne, tendencialmente, de "porcelana", fazendo com que todos os familiares, com os filhos em primeiro lugar, vivam sob a coacção silenciosa dum fantasma de morte iminente, em consequência de episódios de alguma tensão, quaisquer que eles sejam (com os transplantados cardíacos em maior destaque). E chamo, ainda, à atenção para o modo como um transplante pode, perigosamente, tornar-se um aliado importante do divórcio amoroso, porque não dá espaço ao conflito, porque não favorece a autonomia e a emancipação dos membros duma relação, e porque atropela - de forma irreparável - a sexualidade do casal. Com consequências diversas, claro, que se manifestam de forma mais exuberante, uma vez mais, no transplante cardíaco. 


\section{3.}

Como se não bastasse toda esta imensa complexidade psíquica e relacional - que, repito, pode ter, também, intercorrências a nível imunitário - e por mais que os doentes transplantados sejam pessoas escolarizadas, educadas e diferenciadas - um transplante traz consigo, à medida que o tempo passa - ora de forma subtil (através de pesadelos, por exemplo) ora de forma franca (através de manifestações colaterais de natureza hipocondríaca) "fantasmas" diversos. Isto é: medos irracionais que, como estrelas cadentes, atravessam, muitas vezes, o pensamento destas pessoas. E, criando enredos confabulados de forma clandestina, o parasitam.

Basicamente, porque uma pessoa passa a dispor dum órgão de alguém que morreu (o nojo, relembro-vos, é uma emoção básica...). Como se não bastasse o privilégio de ter sido resgatado para a vida, o transplante faz com que uma pessoa sinta que um órgão transplantado se manifesta como uma parte de si, irreparavelmente estranha. Não se manifestando essa angústia de forma aberta, ela parece irse traduzindo numa progressiva iliteracia emocional como se, fosse qual fosse o orgão transplantado, existisse um estranho no coração. Esses enredos fantasmáticos (que repito - se vão organizando de forma mais ou menos difusa no imaginário do doente transplantado) podem trazer, ainda, consigo fantasias sobre quem seria o dador, em que circunstâncias ela morreu e de que forma a sua presença dentro do corpo (através do orgão doado) pode trazer reacções emocionais ou características de comportamento do dador. Quase como se duma "possessão demoníaca" se tratasse.

\section{4.}

Talvez, em mais nenhum outro contexto da actividade médica, a relação médico-doente transplantado se aproxime tanto como duma atmosfera divina. Porque em mais nenhuma como nesta, o médico reserve em si recursos tão próximos de Deus. Que, podendo promover adesão do doente aos procedimentos terapêuticos que o protejam, pode, também, enviesar a relação medico-doente a ponto de não existir a paridade ética que permita ao cirurgião conseguir imaginar uma inversão de papéis, com tudo o que com isso se traduz em gestos amigos da clínica e da ética.

Aliás, se a própria equipa tem, no seu todo, o raro privilégio de resgatar para a vida pessoas "à beira dum abismo", os níveis de exigência brutais que lhe são pedidos torna expectável que os índices de conflito, dentro da própria equipa de transplantes, tenham de ser, a espaços, muito significativos, sob pena de, ao não se manifestarem de forma declarada, aumentarem o risco de doença física ou doença mental graves, de alguns dos seus elementos, no médio/longo prazo.

Também por tudo isto, a inserção dum técnico de saúde mental em equipas médicas desta natureza pode ser um factor precioso de promoção da saúde e de prevenção da doença (profissional...) dos próprios técnicos.

\section{5.}

Falei-vos de níveis mais ou menos silenciosos de doença mental e da forma como eles se expressam, empiricamente,no dia a dia da vossa actividade clínica;

Falei-vos da forma como os factores psicológicos talvez representem o papel mais preponderante a nível das mais diversas doenças;

Falei-vos do estado de choque que acompanha um transplante, e do modo como ele se aproxima dum estado de quase-morte;

Falei-vos das reacções psicopatológicas que, muito tempo depois dum transplante, são expectáveis;

Falei-vos dos custos pessoais, relacionais e familiares dum processo de transplantação;

Falei-vos de aspectos fantasmáticos que ele traz consigo e que, muitas vezes, inquinam algum desequilíbrio psíquico que ele mobiliza;

Falei-vos dos recursos psicológicos que, a meu ver, deveriam alocar às vossa equipas;

E não vos falei da ética, porque acredito que, sem conhecermos mais em pormenor as variáveis psicológicas do doente transplantado, será difícil que nos relacionemos de forma paritária e humana com ele.

Tentei, por fim, dizer-vos que a função da equipa de transplantes estará, algures, entre a cirurgia e a ressuscitação. E que isso pode correr o risco de fazer com que o médico se sinta tão perigosamente divino que, sem que seja transplantado, também ele possa passar a ter (contra o seu desejo, claro) ... um estranho no coração. 